\title{
Effect of variations in prey abundance on growth and development of crab larvae reared in the laboratory and in large field-deployed enclosures
}

\author{
James M. Welch, Charles E. Epifanio \\ College of Marine Studies, University of Delaware, Hugh R. Sharp Campus, Lewes, Delaware 19958, USA
}

\begin{abstract}
We reared larvae of the Atlantic mud crab Panopeus herbstii (Milne-Edwards) in small laboratory bowls and in large field-deployed enclosures with varying prey abundances. Laboratory experiments used brine shrimp nauplii (Artemia sp.) as prey, with abundances ranging from 500 to $10000 \mathrm{l}^{-1}$. Enclosure experiments used wild zooplankton as prey at natural abundances ranging from 10 to 500 zooplankters $1^{-1}$. Results of laboratory experiments showed a strong response to low prey abundance. Dry-weight growth, survival, and development rates of larvae reared at low prey abundances all decreased significantly. Increases in prey abundances above standard culture conditions (5000 Artemia $1^{-1}$ ) had little effect. Results of enclosure experiments showed no response to variations in prey abundance or larval density. No significant differences were found in dry-weight growth, survival, or development rates. The results indicate that larvae can develop successfully at prey densities previously thought incapable of supporting growth. The data also corroborate earlier work suggesting that growth and development are separate processes which can be decoupled.
\end{abstract}

KEY WORDS: Crab larvae $\cdot$ Prey abundance $\cdot$ Growth $\cdot$ Development

\section{INTRODUCTION}

One of the fundamental questions in ecology concerns those factors that control interannual variations in populations of marine animals. Although this question has received much study, it is still not well understood. It has been shown that the supply of larvae influences the size of adult populations in some intertidal invertebrates (Roughgarden et al. 1988, Sutherland 1990). Factors influencing the supply of larvae to recruitment sites include advective transport and larval mortality.

Among the invertebrates, advective transport has been most intensively studied in the brachyuran crabs (e.g. Epifanio 1988a, 1994). Work in this area has yielded a coherent data base concerning the field distributions of several species (e.g. Epifanio 1988b, Epifanio et al. 1989, Dittel \& Epifanio 1990), and recent investigations have identified physical factors driving the dispersal and recruitment of these larval forms (Epifanio 1988a, Goodrich et al. 1989, Little \& Epifanio 1991).
Larval mortality can be affected by variations in temperature, salinity, predation, and prey abundance. A great deal of work has considered abiotic factors, such as temperature and salinity (e.g. Costlow et al. 1962, Brown et al. 1992). In general, low temperatures tend to delay development, and larvae develop best at species-specific salinity optima. Predation is probably the most important single cause of larval mortality (Morgan 1987, 1989, 1990). In fish larvae it has been postulated that predation losses can be modulated by prey availability. Houde $(1987,1989)$ suggests that low prey availability can extend larval periods, and since larvae are subject to high levels of predation, any increase in larval duration can greatly increase total exposure to predation. However, the relationship between feeding environments and larval survival has not received extensive study in decapod crustaceans as it has in fish.

The limited investigations with crab larvae suggest that both the quantity and quality of prey are important. Larvae have a need for cholesterol and for longchain polyunsaturated fatty acids (PUFA). Larvae do 
not have the capability to synthesize cholesterol de novo (Whitney 1969, 1970). Cholesterol is a precursor of the molting hormone ecdysone, so without dietary intake of cholesterol, molting would not be possible (Kanazawa \& Teshima 1971). Artemia strains which are low in 20:5 03 PUFA do not support growth and development as well as strains which are high in 20:5 13 PUFA (Fujita et al. 1980). Sulkin $(1975,1978)$ suggests that the reason that the rotifer Brachionus plicatilis does not support development of Callinectes sapidus larvae to metamorphosis is their low lipid content.

Decapod larvae are considered to be encounter feeders relying on chance meetings with prey items. This has been demonstrated for 3 species by Paul et al. (1979) and for Hyas araneus by Anger \& Nair (1979). Thus, prey density should have a large effect on feeding rates, and consequently larval survival. Welch \& Sulkin (1974) examined the effect of variations in prey concentration on mortality and development of Rithropanopeus harrisii larvae in the laboratory and found an increase in larval duration at low densities, with no variation in survival. Brick (1974) found no variation in larval duration, but did find lower survival at low prey densities in Scylla serrata. McConaugha (1985) concluded that the response of low prey abundance is species-specific. However, all of the early work on 'low' prey abundances actually used very high prey levels compared to natural prey densities (ranging up to 20000 Artemia $1^{-1}$ and only down to $2000 \mathrm{l}^{-1}$ ).

Anger (e.g. 1984, 1987) has studied the effects of starvation for various periods on development and growth of crustacean larvae, but not low food levels. Only 1 major study has attempted to correlate synchrony of larval hatching and production peaks with larval survival in the field (Shirley \& Shirley 1989), and this study found no significant relationship. In a major review of planktotrophic marine invertebrate larvae, Olson \& Olson (1989) determined that prey limitation is frequently manifested in crustacean larvae, while it is less common in mollusk larvae and rare in echinoderm larvae.

To add to the problem of scarce laboratory data regarding feeding environments, the application of these data to the natural environment has recently been called into question. Work by Epifanio and coworkers $(1991,1994)$ in field-deployed enclosures has shown that there are significant differences in growth and development between crabs reared in the laboratory and those reared in enclosures. In other studies, fish reared in enclosures grew and survived at prey densities which did not support survival in the laboratory (e.g. Houde 1987, Cowan \& Houde 1990).

Because the densities of both larvae and prey in the enclosures approach those found in the natural envi- ronment, it is reasonable to assume that the enclosures more closely simulate the real world than does the laboratory. It thus becomes important to examine the effects of variations in feeding environments in the enclosures before extrapolating the laboratory data to open water. Goshorn \& Epifanio (1991) used the results of laboratory studies to develop a mathematical model which predicts the survival of weakfish Cynoscion regalis larvae in Delaware Bay. The model predicts an $11 \mathrm{~d}$ range in the duration of larval development, dependent upon food availability. This difference in time for development would have a large effect on total survival, especially in environments where predation and the possibility of advective transport to unfavorable habitat were great.

The present work examines the effects of variations in prey abundance on growth, survival, and development of crab larvae. We conducted laboratory experiments to allow comparison to previous work and enclosure experiments to determine if the laboratory results can be easily extrapolated into the field. We chose the Atlantic mud crab Panopeus herbstii (Milne-Edwards) as an experimental animal because it is readily available and easy to culture. The larval stages have been characterized for some time (Costlow \& Bookhout 1961), and there is a large body of work using this animal (e.g. Costlow et al. 1962, Epifanio et al. 1991, 1994).

\section{MATERIALS AND METHODS}

Ovigerous Atlantic mud crabs were collected from the University of Delaware Harbor (ca $40^{\circ} \mathrm{N}, 75^{\circ} \mathrm{W}$ ) and held in individual $20 \mathrm{~cm}$ diameter fingerbowls filled with filtered seawater $\left(30 \%, 25^{\circ} \mathrm{C}, 14 \mathrm{~h}\right.$ light: $10 \mathrm{~h}$ dark). Eggs hatched within $5 \mathrm{~d}$ of collection, and zoea larvae were cultured under similar conditions. Larvae from at least 3 females were mixed in all experiments. We conducted separate laboratory and field experiments to determine the effect of variations of prey concentration on dry-weight growth, survival, and development time.

Laboratory experiments. Newly hatched larvae were placed in small fingerbowls with $50 \mathrm{ml}$ of filtered seawater and an appropriate quantity of freshly hatched brine shrimp nauplii (Artemia sp., San Francisco Bay strain). Each day, all surviving larvae were transferred to new bowls with fresh seawater and prey, at which time larvae were counted and the number of molts recorded.

We ran 2 experiments, 1 to give a time series of growth, mortality, and development, and 1 to determine the weight of newly metamorphosed megalopae. The prey densities were 500, 1000, 5000, and 
10000 Artemia nauplii $1^{-1}$. We chose these densities to represent standard culture conditions $\left(5000 \mathrm{l}^{-1}\right)$, excess prey, and 2 low prey densities. In the time series experiment, we removed 1 randomly selected bowl from the experiment each day. Larvae from that bowl were examined to determine zoea stage (Costlow \& Bookhout 1961) and then dried $\left(60^{\circ} \mathrm{C}, 48 \mathrm{~h}\right)$ and weighed on a Mettler microbalance. Because of their small size, zoea stage I and II larvae were weighed in groups of 3 . Later stage larvae were weighed individually. Growth in Panopeus herbstii larvae has been shown to be exponential (Epifanio et al. 1991), so we fitted the growth curve for each prey level to an exponential model using least squares regression:

$$
\ln W_{t}=\ln W_{0}+G t
$$

where $W_{t}$ is the weight at time $t$ days, $W_{0}$ is the weight at the beginning of the experiment, and $G$ is the instantaneous growth coefficient. We considered the harvested bowl to be representative of the weight and developmental stage of all bowls.

Mean daily survival was determined using all remaining bowls in the experiment. We used these data to calculate rates of mortality. We again fitted the data to an exponential model using least squares regression:

$$
\ln N_{t}=\ln N_{0}-Z t
$$

where $N_{t}$ is the mean number of larvae surviving in each bowl on day $t, N_{0}$ is the initial number of larvae, and $Z$ is the instantaneous mortality coefficient. Growth and mortality coefficients were compared among treatments using ANCOVA, with day as the covariate. The time series experiment was terminated at $11 \mathrm{~d}$ post hatching, which encompassed the entire zoeal development of Panopeus herbstii. We ran time series only through the period of zoeal development because previous work (Epifanio et al. 1994) indicated that dry-weight growth is exponential only through this phase of development.

For the megalopa-weight experiment, zoea larvae were reared from hatching until they molted to the megalopa stage. The prey levels and other culture conditions were the same as in the time series experiment. Megalopae were preserved, dried, and weighed as above. We determined differences in weights and development times between treatments using a nested $\mathrm{ANOVA}_{\text {; }}$ in this analysis replicate bowls were nested inside each treatment variable, with individual larvae as variates. Differences in survival were determined by a 1-way ANOVA.

All statistical tests were run using SYSTAT version 5.0 , and differences were considered significant at an experiment-wise $\alpha$-level of 0.05 .
Field experiments. Field experiments were conducted in large field-deployed enclosures (Fig. 1). The enclosures were modelled after de Lafontaine \& Leggett (1987a) and have been used previously in studies with fish larvae (Duffy \& Epifanio 1994) and Panopeus herbstii larvae (Epifanio et al. 1991, 1994). Enclosures were $1 \mathrm{~m}$ diameter cylinders, $3 \mathrm{~m}$ deep. The walls were made of Dacron sailcloth $(25 \mu \mathrm{m}$ nominal pore size), and the bottom $1 \mathrm{~m}$ of each enclosure was a cone made of Nitex mesh $(53 \mu \mathrm{m})$. The bottom of the cone was fitted with a removable cod end for sample collection. The total volume of each enclosure was $1440 \mathrm{l}$. In each experiment, 12 identical enclosures were suspended from 2 rafts moored near the mouth of Delaware Bay. The top $0.5 \mathrm{~m}$ of each enclosure was left out of the water to prevent overwash of waves into the enclosures. On the day of hatching, larvae were placed in plastic bags for transport to the field site. The bags were allowed to float in the enclosures for a minimum of $30 \mathrm{~min}$ to allow thermal equilibration before the larvae were released. A temperature recorder was deployed at $1 \mathrm{~m}$ depth to monitor the temperature at hourly intervals. At the mid-point of each experiment, we measured temperature, salinity, and dissolved

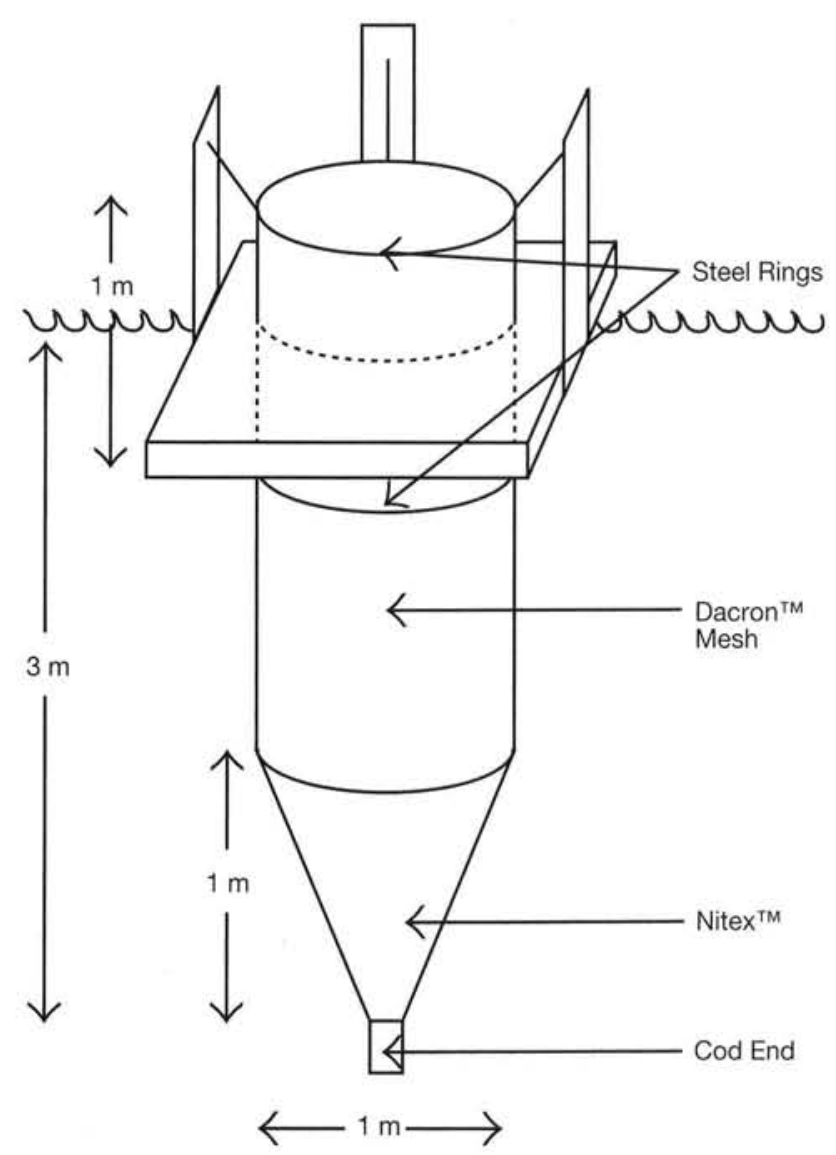

Fig. 1. Enclosures used in field experiments 
oxygen both inside and outside of the enclosures every $2 \mathrm{~h}$ through a complete tidal cycle.

Experimental prey consisted of zooplankton collected near the field site $(100 \mu \mathrm{m}$ mesh, $1.0 \mathrm{~m}$ diameter plankton nets). Zooplankton were sieved through a $253 \mu \mathrm{m}$ sieve to exclude unsuitable prey items and obvious predators, and were concentrated on a $53 \mu \mathrm{m}$ sieve. The density of the concentrated zooplankton was determined by averaging the counts of prey items in three $1 \mathrm{ml}$ aliquots, and appropriate amounts of zooplankton were added to each enclosure volumetrically. On alternate days, we sampled the zooplankton in 1 enclosure from each treatment with a submersible bilge pump. One liter was pumped from each of 3 depths $(0.5,1.0$, and $1.5 \mathrm{~m})$. The sample was concentrated in the laboratory, and zooplankton were counted and identified using standard keys. The mean count of the 3 samples was used as the prey abundance in the enclosure. Preliminary experiments showed that this sampling technique gave accurate measurements of prey abundance. If the prey concentration had dropped below the nominal level, freshly caught zooplankton were added to all of the enclosures in that treatment on the following day.

Larvae were retrieved at the end of the experiment by slowly lifting the enclosures while spraying the inside walls with a saltwater hose. Experimental larvae were concentrated in the cod end and preserved in $4 \%$ formaldehyde. Larvae were removed from the samples, counted and staged. A sample of 40 randomly selected larvae from each enclosure was dried and weighed as above. Dry weights were compared among treatments using a nested ANOVA design with enclosures nested inside treatments. Development was evaluated as the percentage of larvae in the most advanced stage in each experiment. Growth and mortality were assumed to be exponential (Epifanio et al. 1991) and instantaneous growth and mortality coefficients for each treatment were calculated as:

$$
G=\left(\ln W_{\mathrm{f}}-\ln W_{0}\right) / t
$$

where $G$ is the exponential growth coefficient, $W_{\mathrm{f}}$ is the dry weight at the end of the experiment, $W_{0}$ is the dry weight at hatching, and $t$ is the length of the experiment in days. Mortality coefficients were calculated by a similar formula.

We conducted 2 main experiments in the enclosures. The first examined the effect of varying prey density, while the second examined the effect of varying larval density. The varying prey experiment was run in early July 1992, and the prey levels were 10, 50, 100, and 500 prey items $1^{-1}$. These densities span the range of zooplankton densities found in Delaware Bay during the summer (Goshorn \& Epifanio 1991). For this experiment, larvae were stocked at 1 larva $1^{-1}$, approxi- mately the density of larvae found in Delaware Bay. The varying larval stocking density experiment was run in late July 1993, and larvae were stocked at 0.5 , $1.0,1.5$, and 2.0 larvae $1^{-1}$. The prey was 100 zooplankters $\mathrm{l}^{-1}$.

We also conducted a preliminary experiment to determine the effectiveness of the retrieval method. We placed 400 stage IV larvae in each of 4 enclosures; after $3 \mathrm{~h}$, the enclosure was retrieved and washed down as above. The collected larvae were preserved and counted, and the retrieval efficiency calculated. All survival measurements were corrected to account for losses due to retrieval.

\section{RESULTS}

\section{Laboratory experiments}

In the time series experiment there was a trend in dryweight growth: higher prey abundances resulted in higher growth rates (Table 1); however, only the 10000 and 500 Artemia $^{-1}$ treatments were statistically different. We concluded that the exponential model adequately described growth since $\mathrm{r}^{2}$ values derived from the regression were all high (Table 1). Survival showed an exponential decline in the 5000 and $100001^{-1}$ treatments, and was significantly higher in the $100001^{-1}$ treatment (Fig. 2). In the low prey treatments, mortality was greater than predicted by an exponential model, and the decline in log survival was not linear (Fig. 2).

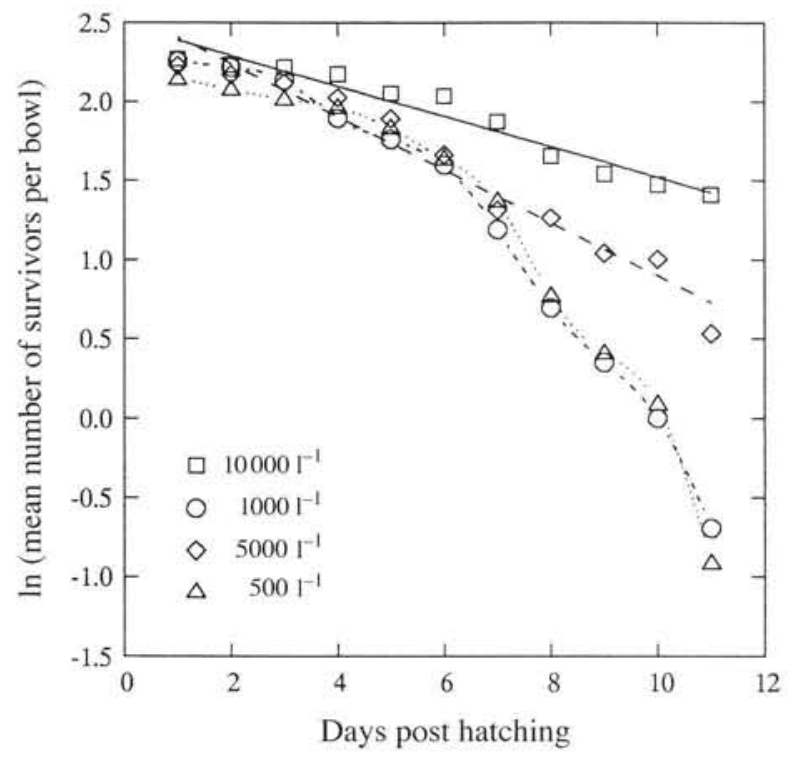

Fig. 2. Panopeus herbstii. Survival of larvae reared in the laboratory with varying prey abundance. Lines for 10000 and 5000 Artemia $1^{-1}$ treatments are regressions showing exponential model for mortality 
Durations of larval stages were virtually identical in the 2 highest prey abundances (Fig. 3). Stage durations increased by about 1.5 to $2.0 \mathrm{~d}$ in the $500 \mathrm{l}^{-1}$ treatment and by $0.5 \mathrm{~d}$ in the $10001^{-1}$ treatment.

In the megalopa-weight experiment, we found a linear relationship between prey abundance and the weight of a megalopa at metamorphosis (Fig. 4). Weights ranged from approximately $43 \mu \mathrm{g}$ for crabs fed 500 Artemial $^{-1}$ to $75 \mu \mathrm{g}$ for crabs fed 10000 Artemial $^{-1}$. There was no significant difference between the 5000 and $10000 \mathrm{l}^{-1}$ treatments in either survival to megalopa or mean time to megalopa (Table 2). The $1000 \mathrm{I}^{-1}$ treatment had lower survival and longer development time than the more well-fed treatments, and the $500 \mathrm{l}^{-1}$ treatment had even less survival and longer development time (Table 2).

\section{Field experiments}

In the varying prey experiment, we had some difficulty keeping the low prey abundances at their nominal levels. Prey abundance in the 10 zooplankter $1^{-1}$ treatment rose to $271^{-1}$ and in the $501^{-1}$ treatment rose to $641^{-1}$. However, all treatments were always different from each other. The prey assemblage consisted mostly of copepods and copepod nauplii, and its composition is given in Table 3 . Physical and chemical conditions inside the enclosures were virtually identical to those in the surrounding waters (Fig. 5). The temperature at $1 \mathrm{~m}$ depth during the larval stocking density experiment is shown in Fig. 6. The average temperature was $21.8^{\circ} \mathrm{C}$. Conditions were similar in the varying prey experiment.

We found no significant effect of variations in prey abundance on the growth rate, survival, or development of the larvae (Table 4). Taking the average of all

Table 1. Panopeus herbstii. Exponential growth and mortality coefficients for larvae reared in the laboratory with varying prey abundance. Dashes indicate that results did not fit an exponential model

\begin{tabular}{|ccccc|}
\hline $\begin{array}{c}\text { Prey abundance } \\
\left(\text { Artemia } ~^{-1}\right)\end{array}$ & $\begin{array}{c}\text { Growth } \\
(G)\end{array}$ & $\mathrm{r}^{2}$ & $\begin{array}{c}\text { Mortality } \\
(Z)\end{array}$ & $\mathrm{r}^{2}$ \\
\hline 10000 & 0.192 & 0.93 & 0.097 & 0.95 \\
5000 & 0.184 & 0.88 & 0.168 & 0.96 \\
1000 & 0.151 & 0.91 & - & - \\
500 & 0.108 & 0.69 & - & - \\
\hline
\end{tabular}

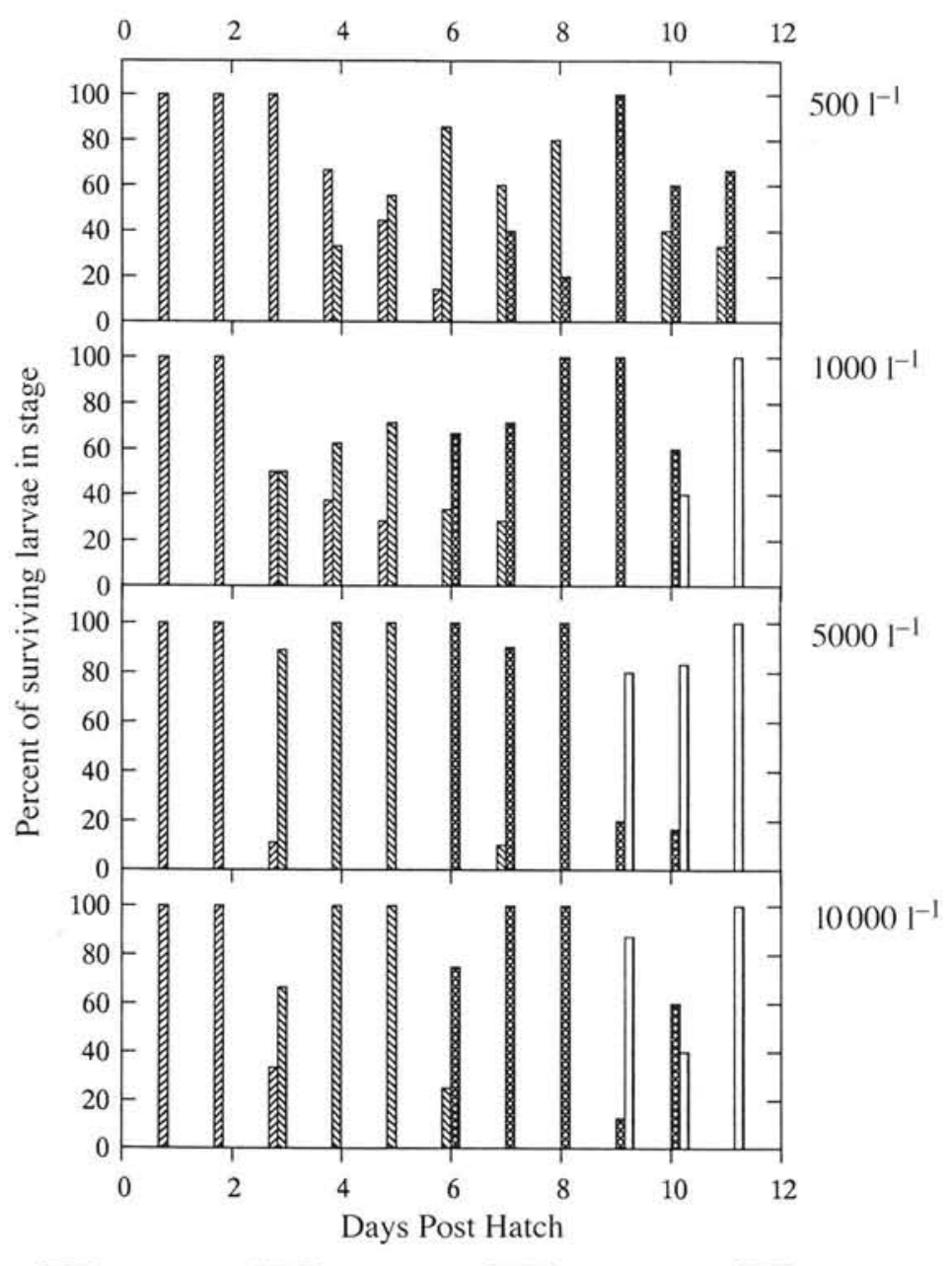

Fig. 3. Panopeus herbstii. Development of larvae reared in the laboratory with varying prey abundance

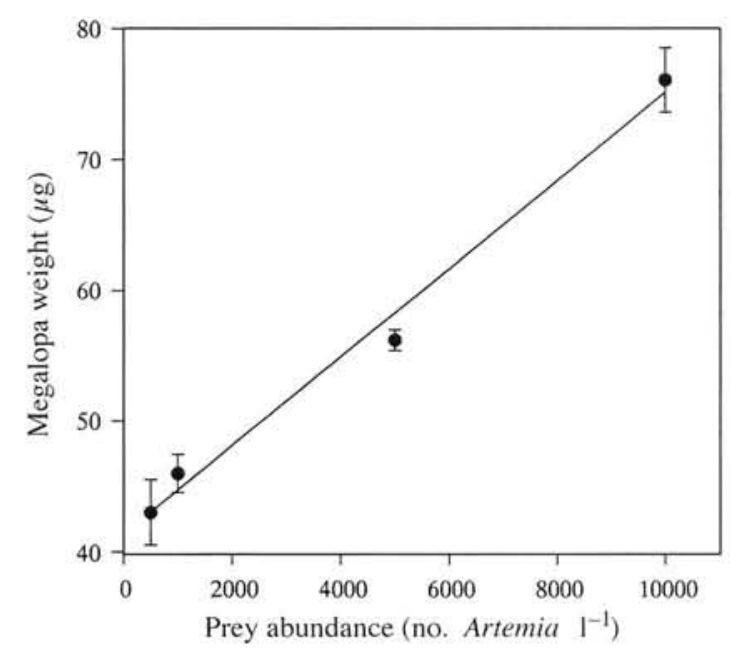

Fig. 4. Panopeus herbstii. Dry weights of megalopae at metamorphosis reared in the laboratory with varying prey abundance. Error bars are $\pm 1 \mathrm{SE}$ 
Table 2. Panopeus herbstii. Survival to megalopa, time for development to megalopa, and instantaneous growth coefficients for larvae reared in the laboratory with varying prey (Artemia sp.) abundance. Values are means ( $\pm 1 \mathrm{SE}$ )

\begin{tabular}{|cccc|}
\hline $\begin{array}{c}\text { Prey abundance } \\
(\text { Artemia 1 }\end{array}$ & $\begin{array}{c}\text { Survival } \\
(\%)\end{array}$ & $\begin{array}{c}\text { Time } \\
(\mathrm{d})\end{array}$ & $\begin{array}{c}\text { Growth } \\
\text { coeff. }\left(\mathrm{d}^{-1}\right)\end{array}$ \\
\hline 10000 & $90.0(0.0)$ & $14.1(0.1)$ & 0.205 \\
5000 & $84.4(0.3)$ & $14.5(0.1)$ & 0.179 \\
1000 & $60.0(0.4)$ & $19.3(0.3)$ & 0.124 \\
500 & $38.6(0.3)$ & $24.1(0.8)$ & 0.097 \\
\hline
\end{tabular}

Table 3. Composition of zooplankton prey in enclosure experiments. Values are percent of total individuals

\begin{tabular}{|lcc|}
\hline Zooplankter & $\begin{array}{c}\text { Varying prey } \\
\text { abundance } \\
\text { experiment }\end{array}$ & $\begin{array}{c}\text { Varying larval } \\
\text { abundance } \\
\text { experiment }\end{array}$ \\
\hline Acartia sp. & 17 & 2 \\
Paracalanus sp. & 2 & 5 \\
Other copepods & 11 & 1 \\
Copepod nauplii & 31 & 34 \\
Trochophores & 8 & 57 \\
Rotifers & 26 & 0 \\
Other & 5 & 1 \\
\hline
\end{tabular}

points, we calculated overall exponential growth and mortality coefficients and found them to be 0.24 and 0.11 respectively.

In the larval stocking density experiment, we found no significant effect of varying larval density on dryweight growth, survival, or development rate (Table 5). Using the average of all points, we again calculated overall exponential growth and mortality coefficients, and found them to be 0.24 and 0.29 respectively. Prey levels were virtually identical between treatments, and the composition of the prey is given in Table 3 .
The results of the retrieval experiment showed that our retrieval method was highly effective; we recovered $94.5 \pm 3.4 \%$ (mean $\pm \mathrm{SD}$ ) of the larvae. All mortality estimates were adjusted to account for losses due to retrieval.

\section{DISCUSSION}

Results in the laboratory confirm earlier studies and extend their findings to much lower prey densities than have been tested in the past - larvae reared in the laboratory are very sensitive to low prey abundances. Survival, dry-weight growth rates, and development rates all decreased significantly in both of the low prey abundances tested. This was true in both the time series and the megalopa-weight experiment. It is important to note that our prey abundances of 500 and 1000 Artemia $1^{-1}$ are among the lowest ever tested. Early investigators tested abundances only down to 2000 Artemia l $^{-1}$, and up to $40000 \mathrm{l}^{-1}$ (e.g. Mootz \& Epifanio 1974, Welch \& Sulkin 1974). Using these abundances, they found a reduction in survival and development only when the prey was below $5000 \mathrm{l}^{-1}$. and no effect of variations in prey above $10000 \mathrm{I}^{-1}$. The previous evidence for a difference between 5000 and $10000 \mathrm{l}^{-1}$ is equivocal. In our megalopa-weight experiment, survival was unaffected by this difference, but it was affected in the time series experiment (Fig. 3, Table 1). The opposite was true for dry-weight growth; in the megalopa-weight experiment, the increased ration resulted in a larger weight at molting to the megalopa stage, while there was no significant difference in growth rates in the time series experiment. Exponential growth coefficients for the 2 experiments were virtually identical, showing that a small difference in exponential growth rate can result in a
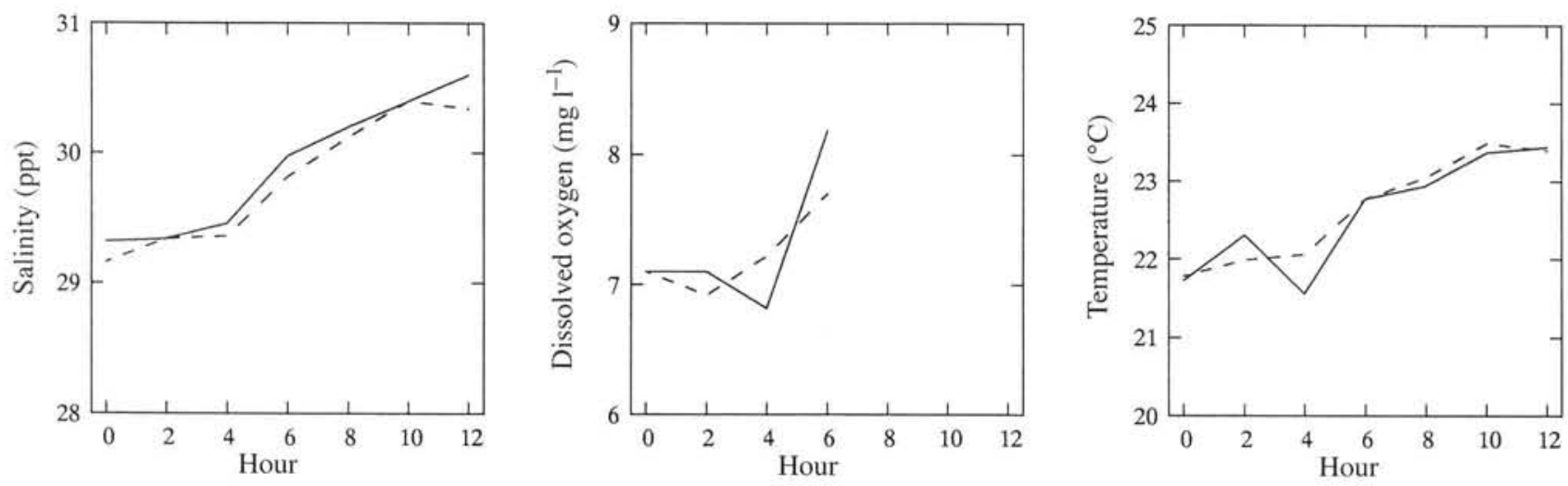

Fig. 5. Physical and chemical conditions inside and outside of enclosures measured throughout a tidal cycle in Delaware Bay. Measurements began at 07:00 h and continued for $12 \mathrm{~h}$. Solid lines indicate measurements outside enclosures, dashed lines indicate inside. The oxygen meter failed after $6 \mathrm{~h}$ 


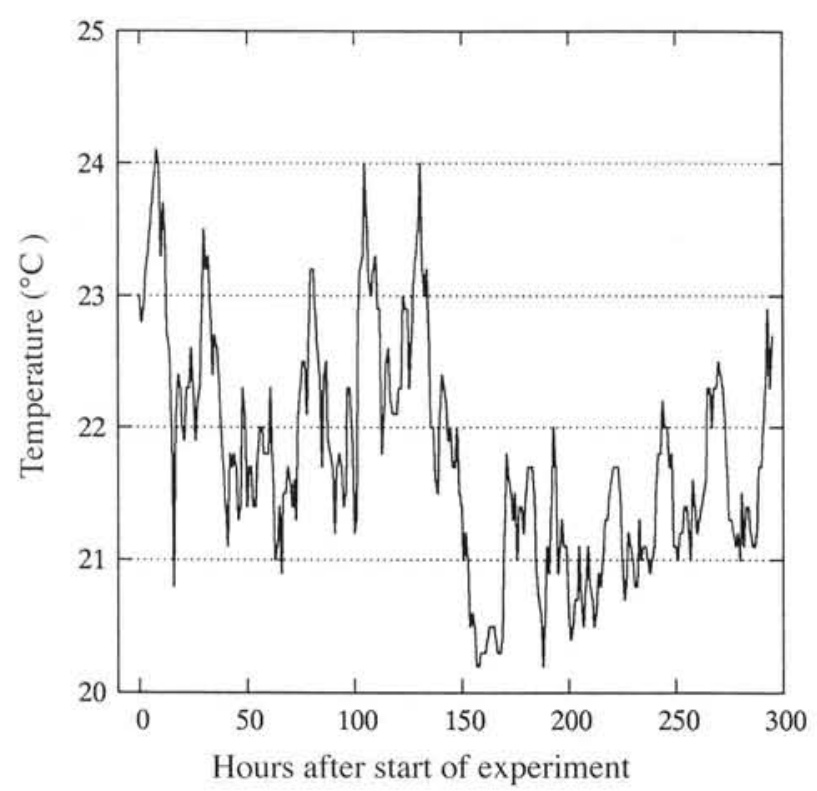

Fig. 6. Temperature measured at $1 \mathrm{~m}$ depth at hourly intervals during the varying larval density experiment, July 31 to August 11, 1993

significant weight difference later in development. The different weights of megalopae in the megalopaweight experiment also corroborate work by Epifanio et al. (1994) suggesting that growth and development are separate processes which can be decoupled. An important conclusion from these data is the fact that larvae can survive to metamorphosis at field prey densities. This is the first study to rear larvae through metamorphosis at these densities.

In contrast to the laboratory results, we found no effect of variations in prey density in the enclosures. There were no significant differences in dry-weight growth, survival, or development. We did have some difficulty maintaining prey at the desired abundances at the lowest treatment levels; however, the 10 zooplankter $\mathrm{l}^{-1}$ treatment never got above $30 \mathrm{l}^{-1}$, and the $501^{-1}$ treatment never got above $701^{-1}$. The prey abundances were significantly different at all times, but these differences did not affect the larvae in any meas-

Table 4. Panopeus herbstii. Dry weights, survival and development of larvae reared in enclosures with varying prey, harvested on Day 7. Values are means ( \pm 1 SE)

\begin{tabular}{|cccc|}
\hline $\begin{array}{c}\text { Prey abundance } \\
\left(\text { Zooplankters 1 }{ }^{-1}\right)\end{array}$ & $\begin{array}{c}\text { Dry wt } \\
(\mu \mathrm{g})\end{array}$ & $\begin{array}{c}\text { Survival to } \\
\text { Day } 7(\%)\end{array}$ & $\begin{array}{c}\% \text { in stage III } \\
\text { on Day 7 }\end{array}$ \\
\hline 500 & $18.7(0.6)$ & $41.7(22.3)$ & $89.9(1.7)$ \\
100 & $20.1(0.8)$ & $72.4(21.3)$ & $92.1(0.3)$ \\
50 & $19.5(0.4)$ & $25.1(4.5)$ & $90.5(1.1)$ \\
10 & $19.0(0.3)$ & $42.1(16.3)$ & $90.9(1.1)$ \\
\hline
\end{tabular}

Table 5. Panopeus herbstii. Dry weights, survival and development of larvae reared in enclosures with varying larval density, harvested on Day 11 . Values are means ( $\pm 1 \mathrm{SE}$ )

\begin{tabular}{|cccc|}
\hline $\begin{array}{c}\text { Larval abundance } \\
\left(\text { larvae }{ }^{-1}\right)\end{array}$ & $\begin{array}{c}\text { Dry wt } \\
(\mu \mathrm{gg})\end{array}$ & $\begin{array}{c}\text { Survival to } \\
\text { Day 11 }(\%)\end{array}$ & $\begin{array}{c}\% \text { in stage IV } \\
\text { on Day 11 }\end{array}$ \\
\hline 2.0 & $55.2(4.2)$ & $4.9(4.0)$ & $92.8(2.4)$ \\
1.5 & $54.5(0.8)$ & $4.7(2.0)$ & $92.2(2.9)$ \\
1.0 & $55.1(4.4)$ & $4.9(1.9)$ & $94.7(1.1)$ \\
0.5 & $50.3(4.0)$ & $2.8(1.8)$ & $98.1(1.9)$ \\
\hline
\end{tabular}

urable way. The survival of the larvae at the lowest prey abundance suggests that larvae are well adapted to survive even very low prey abundances in nature.

Variations in larval density also had no effect on growth rate, survival, or development. This could be due to the relatively small spread in densities used; the highest density was only 4 times the lowest density. We would have preferred to test larger density differences, but the high mortality exhibited in the enclosures required a relatively large number of larvae for the lowest treatment, and limited larval supply prohibited testing very high densities.

Larvae grew well in enclosures, with instantaneous growth coefficients consistently above $0.20 \mathrm{~d}^{-1}$. However, survival was low, both in the experiments presented here and in other preliminary work. This brings up a very interesting peculiarity of the data - the decorrelation of survival and growth rates. One would expect that in a favorable environment for growth, both growth rate and survival would be high. In this case, the low survival numbers suggest that the enclosures are not favorable, while the high growth rates argue that they are excellent. The facile explanation for this decoupling is a density-dependent response: when many larvae survive, they negatively interact with each other to keep down growth rates, and when few larvae survive, there is less interaction so growth rates increase. However, our results contradict this explanation. We found no variations in growth or survival with varying larval density.

Other possible explanations for the high mortality in the field include unexpected predation or inadequacy of diet, either in amount or in composition. It is clear that a few predators entered the enclosures. There was some overwash, as indicated by the presence of a few large animals in the samples, such as mysid shrimp and stomatopods. However, these large predators were present in insufficient numbers to account for all of the losses (a total of 4 mysids and 2 stomatopods in all experiments). The overwash might have contained carnivorous copepods or other organisms that would have been overlooked in processing the samples. In earlier work in enclosures, Duffy \& Epifanio (1994) 
suggested that predation by carnivorous copepods which completed their development from nauplii or copepodites during the course of the experiment might be a factor contributing to mortality in fish larvae. The carnivorous copepod Oithona sp. accounted for approximately $5 \%$ of the zooplankton assemblage. Cannibalism by the larvae themselves is another possible explanation, but it is unlikely. Cannibalism by megalopae is known to occur in small laboratory containers but is uncommon in zoeae (Epifanio pers. obs.). In addition, cannibalism is seen when larvae are held at high densities typical of laboratory work, and the larvae in the enclosures were at 1 larva $1^{-1}$ or less. The high growth rates make it seem highly unlikely that the diet was nutritionally inadequate, and results indicate that the larvae did not deplete the zooplankton prey to any great extent. In the varying prey experiment, prey levels never dropped below the nominal levels. In the varying density experiment, prey was never below $85 \%$ of the nominal level, and increased at the end of the experiment due to reproductive activity by copepods. Thus, the cause of the high mortality rates in the enclosures remains cryptic.

In general, larvae in the enclosures showed lower survival, faster development, and similar or faster growth compared to larvae in the laboratory. Differences between the 2 environments which could explain these disparities include prey composition, container size, and physical and chemical conditions. Artemia nauplii used in the experiments (San Francisco Bay strain) are high in 20:5 $\omega 3$ PUFA, which are necessary for rapid growth of crab larvae (Fujita et al. 1980). While we do not have exact values, work by Goshorn (1990) found that wild-caught zooplankton, as used in the enclosures, has a lower specific energy content than the Artemia used in the laboratory. This is probably due to a lower overall lipid content, which implies that levels of PUFA would be lower as well. Nonetheless, growth rates in the enclosures were consistently the same as or higher than those in the lab.

Another difference in the nutritional environment between the lab and the enclosures was the inclusion of a natural phytoplankton assemblage in the enclosures. While crab larvae cannot survive on phytoplankton alone, earlier work suggests that phytoplankton may provide ancillary nutrition when fed in combination with animal prey (Brick 1974, Sulkin \& Epifanio 1975). It is likely that larvae ingested some phytoplankton, but again it is unclear what nutritional role it might have played.

Another possible explanation for the differences between the field and the laboratory is the size of the experimental environments. Container size effects are not well understood, but fish larvae can survive in large enclosures at prey densities that do not support growth in small laboratory containers (e.g. de Lafontaine \& Leggett 1987b, Duffy \& Epifanio 1994). One possible explanation is the formation of highly concentrated patches of zooplankton prey in enclosures and their subsequent utilization by larvae (MacKenzie et al. 1990). Thus the crab larvae in our experiments may have been feeding at higher effective densities of prey than indicated by the nominal densities in the enclosures.

The temperatures in the enclosures varied both diurnally and with depth, and averaged about $3^{\circ} \mathrm{C}$ below that in the lab. Costlow et al. (1962) showed that low temperatures significantly retard growth of Panopeus herbstii larvae; nonetheless, in our work the larvae in the cooler environment developed faster. The diurnally cyclic temperature regime in the enclosures may account for some of the difference; similar regimes have been shown to accelerate development in another xanthid, Rithropanopeus harrisii (Christiansen \& Costlow 1975).

It is clear that fundamental differences exist between the laboratory and the enclosures, and that these differences have substantial effects on growth and development of crab larvae. These differences have critical implications for the extrapolation of laboratory data to the field. Physical and chemical conditions in the enclosures were virtually identical to those in the surrounding waters, and the densities of both larvae and prey were chosen to approximate those found in Delaware Bay. In the laboratory, on the other hand, both larvae and their prey were at greatly exaggerated densities compared to the natural conditions. It is clear, then, that larvae in the enclosures experienced conditions that were closer to natural conditions in Delaware Bay, and that estimates of rates of growth and development derived from the enclosures are probably closer approximations to the natural situation than those derived from laboratory culture. A simple extrapolation of results regarding the effect of variations in prey from the laboratory to the field would have given rise to conclusions that are directly contradicted by the field data. The difference was not one of degree - the effect, which was strong in the lab, did not even appear in the field.

Acknowledgements. We thank Brandon Jones, James Yang, Victoria Connaughton, and Janet Duffy for their assistance both in the field and in the lab. This work was supported by Wallop-Breaux Sport Fish Restoration Act funds administered through the Delaware Department of Natural Resources and Environmental Control.

\section{LITERATURE CITED}

Anger, K. (1984). Influence of starvation on moult cycle and morphogenesis of Hyas araneus larvae (Decapoda, Majidae). Helgoländer Meeresunters. 38: 21-33 
Anger, K. (1987). The $\mathrm{D}_{0}$ threshold: a critical point in the larval development of decapod crustaceans. J. exp. mar. Biol. Ecol. 108: 15-30

Anger, K., Nair, K. K. C. (1979). Laboratory experiments on the larval development of Hyas araneus (Decapoda, Majidae). Helgoländer Meeresunters. 34: 287-311

Brick, R. W. (1974). Effects of water quality, antibiotics, phytoplankton and food on survival and development of larvae of Scylla serrata (Crustacea: Portunidae). Aquaculture 3: 231-244

Brown, S. D, Bert, T. M., Tweedale, W. A., Torres, J. J., Lindberg, W. J. (1992). The effects of temperature and salinity on survival and development of early life stage Florida stone crabs Menippe mercenaria (Say). J. exp. mar. Biol. Ecol. 157: 115-136

Christiansen, M. E., Costlow, J. D. (1975). The effect of salinity and cyclic temperature on larval development of the mud crab, Rithropanopeus harrisii (Brachyura: Xanthidae) reared in the laboratory. Mar. Biol. 32: 215-221

Costlow, J. D., Bookhout, C. G. (1961). The larval stages of Panopeus herbstii Milne-Edwards reared in the laboratory. J. Elisha Mitchell Sci. Soc. 77: 33-42

Costlow, J. D., Bookhout, C. G., Monroe, R. (1962). Salinitytemperature effects on the larval development of the crab Panopeus herbstii Milne-Edwards, reared in the laboratory. Phys. Zool. 35: 79-93

Cowan, J. H., Houde, E. D. (1990). Growth and survival of bay anchovy Anchoa mitchilli larvae in mesocosm enclosures. Mar. Ecol. Prog. Ser. 68: 47-57

de Lafontaine, Y., Leggett, W. C. (1987a). Evaluation of in situ enclosures for larval fish studies. Can. J. Fish. Aquat. Sci. 44: $54-65$

de Lafontaine, Y., Leggett, W. C. (1987b). Effects of container size on estimates of mortality and predation rates in experiments with microzooplankton and larval fish. Can. J. Fish. Aquat. Sci. 44: 1534-1543

Dittel, A. I., Epifanio, C. E. (1990). Seasonal and tidal abundance of crab larvae in a tropical mangrove system, Gulf of Nicoya, Costa Rica. Mar. Ecol. Prog. Ser. 65: 25-34

Duffy, J. T., Epifanio, C. E. (1994). The effects of larval density on the growth and survival of weakfish Cynoscion regalis in large-volume enclosures. Mar. Ecol. Prog. Ser. 104: $227-233$

Epifanio, C. E. (1988a). Dispersal strategies of two species of swimming crab on the continental shelf adjacent to Delaware Bay. Mar. Ecol. Prog. Ser. 49: 243-248

Epifanio, C. E. (1988b). Transport of crab larvae between estuaries and the continental shelf. Lect. Notes coast. estuar. Stud. 22: 291-305

Epifanio, C. E. (1994). Transport of blue crab (Callinectes sapidus) larvae in the Middle Atlantic Bight. Bull. mar. Sci. (in press)

Epifanio, C. E., Cope, J. S., Rowe, P. M., Jenkins, F. M. (1991). Comparison of rates of development of Atlantic mud crab larvae in the laboratory and in field-deployed enclosures. J. Crust. Biol. 11: 540-545

Epifanio, C. E., Lobanoff, M. A., Connaughton, V. P., Welch, J. M. (1994). Growth and development of Atlantic mud crab larvae fed natural zooplankton prey. J. exp. mar. Biol. Ecol. (in press)

Epifanio, C. E., Masse, A. K., Garvine, R. W. (1989). Transport of blue crab larvae by surface currents off Delaware Bay, USA. Mar. Ecol. Prog. Ser. 54: 35-41

Fujita, S., Watanabe, T., Kitajima, C. (1980). Nutritional quality of Artemia from different localities as a living feed for marine fish from the viewpoint of essential fatty acids. In:
Persoone, L. G., Sorgeloos, P., Roels, O., Jaspers, E. (eds.) The brine shrimp Artemia, Vol. 3. Universal Press, Wettesen, p. 277-290

Goodrich, D. M., J. van Montfrans, Orth, R. J. (1989). Blue crab megalopal influx to Chesapeake Bay: evidence for a winddriven mechanism. Estuar. coast. Shelf Sci. 29: 247-260

Goshorn, D. M. (1990). Distribution of larval weakfish (Cynoscion regalis) in Delaware Bay and the relationship of field prey concentration to laboratory determined growth and mortality rates. Doctoral Dissertation, College of Marine Studies, University of Delaware, Lewes

Goshorn, D. M., Epifanio, C. E. (1991). Diet of larval weakfish and prey abundance in Delaware Bay. Trans. Am. Fish. Soc. 120: $684-692$

Houde, E. D. (1987). Fish early life dynamics and recruitment variability. Am. Fish. Soc, Symp. 2: 17-29

Houde, E. D. (1989). Subtleties and episodes in the early life of fishes. J. Fish. Biol. 35: 29-38

Kanazawa, A., Teshima, S. (1971). In vivo conversion of cholesterol to steroid hormones in the spiny lobster, Panulirus japonica. Bull. Jap. Soc. scient. Fish. 37: 211-215

Little, K. T., Epifanio, C. E. (1991). Mechanism for the reinvasion of an estuary by two species of brachyuran megalopae. Mar. Ecol. Prog. Ser. 68: 235-242

McConaugha, J. R. (1985). Nutrition and larval growth. In: Wenner, A. M. (ed.) Crustacean issues 2: larval growth. A. A. Balkema, Rotterdam, p. 127-159

MacKenzie, B. R., Leggett, W. C., Peters, R. H. (1990). Estimating larval fish ingestion rates: can laboratory derived values be reliably extrapolated to the wild? Mar. Ecol. Prog. Ser. 67: 209-225

Mootz, C. A., Epifanio, C. E. (1974). An energy budget for Menippe mercenaria larvae fed Artemia nauplii. Biol. Bull. 146: 44-55

Morgan, S. G. (1987). Morphological and behavioral antipredatory adaptations of decapod zoeae. Oecologia 73: $393-400$

Morgan, S. G. (1989). Adaptive significance of spination in estuarine crab zoeae. Ecology 70: 464-482

Morgan, S. G. (1990). Impact of planktivorous fishes on dispersal, hatching, and morphology of estuarine crab larvae. Ecology 71: 1639-1652

Olson, R. R., Olson, M. H. (1989). Food limitation of planktotrophic marine invertebrate larvae: does it control recruitment success? A. Rev. Ecol. Syst. 20: 225-47

Paul, A. J., Paul, J. M., Shoemaker, P. A., Feder, H. M. (1979). Prey concentrations and feeding response in laboratory reared stage one zoeae of king crab, snow crab, and pink shrimp. Trans. Am. Fish. Soc. 108: 440-443

Roughgarden, J., Gaines, S., Possingham, H. (1988). Recruitment dynamics in complex life cycles. Science 241: 1460-1466

Shirley, S. M., Shirley, T. C. (1989). Interannual variability in density, timing, and survival of Alaskan red king crab Paralithodes camtschatica larvae. Mar. Ecol. Prog. Ser. 54: 51-59

Sulkin, S. D. (1975). The significance of diet on the growth and development of larvae of the blue crab, Callinectes sapidus Rathbun, under laboratory conditions. J. exp. mar. Biol. Ecol. 20: 119-135

Sulkin, S. D. (1978). Nutritional requirements during larval development of the portunid crab Callinectes sapidus Rathbun. J. exp. mar. Biol. Ecol. 34: 29-41

Sulkin, S. D., Epifanio, C. E. (1975). Comparison of rotifers and other diets for rearing early larvae of the blue crab Callinectes sapidus Rathbun. Estuar. coast. mar. Sci. 3: 109-113 
Sutherland, J. P. (1990). Recruitment regulates demographic variation in a tropical intertidal barnacle. Ecology 71: 955-972

Welch, J., Sulkin, S. (1974). Effect of diet concentration on mortality and rate of development of zoeae of the xanthid crab, Rithropanopeus harrisii (Gould). J. Elisha Mitchell Sci. Soc. 90: 69-72

This article was submitted to the editor
Whitney, J. O. (1969). Absence of sterol synthesis in larvae of the mud crab Rithropanopeus harrisii, and of the spider crab, Libinia emarginata, Mar. Biol. 3: 134-135

Whitney, J. O. (1970). Absence of sterol biosynthesis in the blue crab, Callinectes sapidus Rathbun and in the barnacle Balanus nubilus Darwin. J. exp. mar. Biol. Ecol. 4: 229-237

Manuscript first received: May 16, 1994

Revised version accepted: September 2, 1994 